\title{
Features of disturbances of functions of cellular membranes in patients with chronic kidney disease, treated with programmed hemodialysis
}

\begin{abstract}
In recent years, there has been a steady increase in the number of patients receiving programmed hemodialysis due to the annual increase in the capacity of the dialysis centers, the progression of socially significant diseases, such as diabetes mellitus, arterial hypertension, etc. In the last decade, there has been a significant improvement in the quality of the dialysis procedure, and as a result, the number of patients with a long-term dialysis experience is growing. ${ }^{1-3}$ Stage 5 chronic kidney disease (CKD) is accompanied by a disturbance of all the functions of the body's systems and is reflected in a change of intracellular processes, including a disturbance of the structural and functional properties of cell membranes. The works from the list of references indicate that destabilization of red blood cell (RBC) membranes can be influenced by such systemic and organ factors as tissue ischemia, microbial or immune inflammation. The level of nonspecific membrane stabilizing processes reveals the nature of damage in organs and organsystems., ${ }^{4,8,17,19}$ In vivo study of the properties of cell membranes can directly and indirectly assess the regulation of all biological processes in the cells of the body. ${ }^{8,15}$ The surface electric charge of the membrane is one of the main physical characteristics of RBC, the value of which is estimated by their electrophoretic mobility.

Electrophoretic mobility of erythrocytes (EME) is the ability of RBC to move in an electric field with a speed depending on the value of their surface electric charge of the membrane. RBC must have a stable value of the surface electric charge for the adequate functioning and maintenance of homeostasis of the body. The physical and chemical state of the cell membrane (along with the composition of the environment surrounding the cell) has a crucial influence on the value of EME. In the literature there are publications indicating a decrease in the electric charge of RBC in sepsis, intestinal diseases, viral diseases, pneumonia, rheumatic diseases, as well as under stress. ${ }^{1-8,16,18,20}$ Terminal conditions, such as CKD 5D, cause changes in the density of the surface electric charge of the blood corpuscles, which are accompanied by a disturbance of the stability of the cell suspension and functional activity of cells. Thus, the electrophoretic mobility of RBC in hemodialysis patients is virtually unexplored. The emergence of new data is necessary, including, information about the impact of drug therapy on the charge of RBC membranes for the further appointment of adequate therapy.
\end{abstract}

Keywords: electrophoretic mobility of erythrocytes, chronic kidney disease, hemodialysis, hypertension, antihypertensive therapy
Volume 8 Issue 2 - 2020

\section{Kazakova Irina Aleksandrovna,Yevgeniy Nikolaevich levlev \\ Department of Internal diseases, Professor, Izhevsk State Medical Academy of the Ministry of Health of the Russian Federation, Russia}

Correspondence: Yevgeniy Nikolaevich levlev, PhD, Assistant of the Department of Internal diseases with courses of radiation diagnostic methods and treatment, Military field therapy, lzhevsk State Medical Academy of the Ministry of Health of the Russian Federation, Address: 28I Kommunarov str., Izhevsk, 426000 , Russia,Tel (34I2)68-68-48, Email vnut.bolezni@mail.ru

Received: March 10, 2020 | Published: April 29, 2020
Abbreviations: $\mathrm{CKD}$, chronic kidney disease; $\mathrm{RBC}$, red blood cell; EME, electrophoretic mobility of erythrocytes; CCB, calcium channel blockers; BB, beta-blockers; AAEO, average amplitude of erythrocyte oscillations

\section{Introduction}

The aim of the research is to identify changes in the electrophoretic mobility of RBC in patients with hypertension treated with programmed hemodialysis.

\section{Materials and methods}

The study included 120 patients with stage 5 CKD (55\%-women, $45 \%$-men) who received program hemodialysis in Izhevsk, Udmurt Republic (BIHC of URMCH №6 of MOH of UR, BIHC of UR RCH№1 of MOH of UR). The average age was $49.7 \pm 9.4$ years. The procedures were performed on the devices "Fresenius " $-4008 \mathrm{~S}$ (Germany) and B. Braun - Dialog+ (Germany) for 4-4.5 hours 3 times a week using polysulfone dialyzers. Only bicarbonate dialysis solution was used during hemodialysis. The $\mathrm{Kt} / \mathrm{V}$ adequacy index for urea was higher than 1.2 and amounted to $1.43 \pm 0.09$. A comparison group was created to identify the features of cell membrane disorders. The group included 60 practically healthy individuals (blood donors), comparable in age and gender. All patients were divided into 3 groups depending on the level of blood pressure (BP): normal, low and high BP. Patients with hypertension were divided into 3 groups according to its grade. Monotherapy with antihypertensive drugs included the use of slow calcium channel blockers (CCB), beta-blockers (BB) and angiotens in-converting enzyme inhibitors (ACE inhibitors).The following treatment regimens were used as combination therapy: combination of $\mathrm{CCB}$ and $\mathrm{BB}, \mathrm{CCB}$ and $\mathrm{ACE}$ inhibitors, $\mathrm{CCB}$ and $\mathrm{I}_{1}$-imidazoline receptor agonist (IRA-Moxonidine), $\mathrm{BB}$ and ACE inhibitors, $\mathrm{CCB}$ with $\mathrm{BB}$ and $\mathrm{ACE}$ inhibitors. The groups were comparable in gender and age.

EME was measured with "CITO-Expert" complex (JSC "Axion 
holding company", Izhevsk, 2010) to assess membrane disorders. It provides the possibility of recording and evaluating the parameters of the movement of living cells under the influence of alternating electric field with adjusted characteristics with the light microscope "Biolam". The percentage of mobile RBC was calculated and the average amplitude of erythrocyte oscillation (AAEO) and asymmetry of oscillation were recorded. Patients underwent ABPM (apparatus MECG-DP-NS-01, 2012) for $23.2+0.6$ hours. The interrelation of biochemical analyses with ABPM was evaluated. Biochemical tests were carried out in accordance with the standards of diagnostics of patients on programmed hemodialysis and included following indicators: creatinine $(780.45 \pm 199.9 \mathrm{mmol} / \mathrm{l})$, urea $(29.4 \pm 6.9$ $\mathrm{mmol} / \mathrm{l})$, potassium $(5.33 \pm 0.47 \mathrm{mmol} / \mathrm{l})$, sodium $(137.7 \pm 2.1 \mathrm{mmol} / \mathrm{l})$, calcium $(2.52 \pm 0.5 \mathrm{mmol} / \mathrm{l})$, phosphorus $(2.1 \pm 0.4 \mathrm{mmol} / \mathrm{l})$, alkaline phosphatase $(311.7 \pm 155.2 \mathrm{U} / \mathrm{l})$, total cholesterol( $5.1 \pm 1.2 \mathrm{mmol} / \mathrm{l})$, parathyroid hormone $(899.3 \pm 728.7 \mathrm{pg} / \mathrm{ml})$. Statistical processing of the results of the study was carried out by the generally accepted methods of variation statistics using the application programs "BioStat" (Primer of Biostatistics, Practise, Moscow, 2009, version 4.03.) and Microsoft Excel 2010 (USA). The data are presented as $\mathrm{M} \pm \sigma$, where $\mathrm{M}$ is the mean value, $\sigma$ is the standard deviation. The differences between the mean values were considered statistically significant at $\mathrm{p}<0.05$. Relation analysis was performed using Spearman rank correlation coefficient $\left(\mathrm{r}_{\mathrm{s}}\right)$.

\section{Results}

Comparing the results of the study of the main group and the comparison group, there was a significant increase in the average amplitude of erythrocyte oscillations (AAEO): the values of AAEO are $49.7+6.3 \mathrm{mcm}$ and $28.4+3.2 \mathrm{mcm}$ (Table $1 ; \mathrm{p}<0.01$ ) respectively. The increase can be associated with serious pathophysiological disorders in patients with CKD that affect cell membranes, which are associated with changes in the hemostatic system and mechanical damage to RBC during the passing through the dialysis filter. Significant differences in asymmetry $-0.98 \pm 1.3,-1.37 \pm 0.2(\mathrm{p}>0.05)$ and excesses $5.1 \pm 6.9,9.62 \pm 1.7(p>0.05)$ respectively, weren't observed in patients treated with programmed hemodialysis and the comparison group. The percentage of mobile RBC didn't differ in hemodialysis patients and donors (table $1, \mathrm{p}>0.05$ ). There were no gender differences in AAEO: in men $-50.6 \pm 6.9 \mathrm{mcm}$, in women $-49 \pm 7.6 \mathrm{mcm}(\mathrm{p}>0.05)$. The differences of AAEO in patients with different duration of dialysis experience were identified: $1-6$ years $-44.8 \pm 8.2 \mathrm{mcm}$, 6 - 10 years $-56.3 \pm 5.5 \mathrm{mcm}$, more than 11 years $-50.6 \pm 2.3 \mathrm{mcm}\left(p_{1}\right.$. $\left.{ }_{2}<0,01, p_{2-3}<0,01\right)$.In the first years of the dialysis therapy, there is a high mortality of patients. At this time there are gross disturbances and rearrangement of biological processes, which can justify more significant decrease in the rates of AAEO in patients with duration of dialysis therapy from 1 year to 6 years $(\mathrm{p}<0.01)$.

Table I Indicators of electrophoretic mobility of RBC

\begin{tabular}{lll}
\hline Indicator & Hemodialysis patients & Donors \\
\hline & $\mathrm{N}=120$ & $\mathrm{~N}=42$ \\
AAEO $(\mathrm{mcm})$ & $48,9 \pm 6,7 * * *$ & $28,4 \pm 3,2$ \\
$\begin{array}{l}\text { Asymmetry of } \\
\text { oscillation }\end{array}$ & $-0,98 \pm 1,3$ & $-1,37 \pm 0,2$ \\
$\begin{array}{l}\text { The percentage of } \\
\text { mobile RBC (\%) }\end{array}$ & $98,6 \pm 15,4$ & $99,2 \pm 1,2$ \\
\hline
\end{tabular}

Note The reliable indicator of differences between groups $-* * * \mathrm{p}<0,000$ I
It was found that the etiological factor of $\mathrm{CKD}$, such as polycystic kidney disease, more significantly reduced AAEO $(48.6 \pm 4.5 \mathrm{mcm}$; $\mathrm{p}<0.01)$. This probably connected with genetically determined disorders of the structure of cell membranes, as well as the presence of chronic inflammation and severe hypertension. The value of AAEO in patients with chronic glomerulonephritis was $49.5 \pm 6.3 \mathrm{mcm}$, with diabetic nephropathy $-50.7 \pm 7.2 \mathrm{mcm}$, with secondary chronic pyelonephritis $-54.7 \pm 4.1 \mathrm{mcm}(\mathrm{p}<0.01)$. Differences in AAEO were identified in patients with hypertension and normal BP: $47.8=6.2 \mathrm{mcm}$ and $54.3=3.7 \mathrm{mcm}$ respectively $(\mathrm{p}<0.01)$. Patients with hypertension had lower (negative) values of erythrocyte oscillation asymmetry than patients with normal BP $(-1.3 \pm 1.2$ and $-0.35 \pm 0.8$ respectively; $\mathrm{p}<0.01)$. No statistically significant differences in the percentage of mobile RBC were obtained in patients with hypertension, with high and low BP, (Table 2). In individuals with 1 grade hypertension, the AAEO was $47.5 \pm 1.4 \mathrm{mcm}$, with 2 grade hypertension $-47.6 \pm 2.8$ $\mathrm{mcm}$, with 3 grade hypertension $-52.7 \pm 3.2 \mathrm{mcm}(\mathrm{p}<0.01$; Table 3$)$. Differences in rate of asymmetry of oscillation of RBC were found. In patients with grade 1 hypertension, the percentage of mobile RBC was significantly higher than in those with grade 3 hypertension $(98.3 \pm 0.7 \%$ and $96.0 \pm 0.9 \%$, respectively; $p<0.05$ ).

Table2 Comparative characteristics of electrophoretic mobility of RBC in groups with different BP levels

\begin{tabular}{llll}
\hline Indicator & Normal BP & Hypertension & Hypotension \\
\hline & $\mathrm{N}=15$ & $\mathrm{~N}=85$ & $\mathrm{~N}=20$ \\
AAEO $(\mathrm{mcm})$ & $54,3 \pm 3,7$ & $47,8 \pm 6,2^{* *}$ & $46, I \pm 7,7$ \\
$\begin{array}{l}\text { Asymmetry of } \\
\text { oscillation }\end{array}$ & $-0,35 \pm 0,8$ & $-1,3 \pm 1,2^{*}$ & $-\mathrm{I} \pm \mathrm{I}, 5$ \\
$\begin{array}{l}\text { The percentage of } \\
\text { mobile RBC }(\%)\end{array}$ & $98,8 \pm \mathrm{I}, \mathrm{I}$ & $98,2 \pm 2,9$ & $98,8 \pm 1,4$ \\
\hline
\end{tabular}

Note: The reliable indicator of differences between groups $-* * p<0,01 ; * \mathrm{p}<0,05$-in comparison with group of patients with normal BP

Table 3 Comparative characteristics of electrophoretic mobility of RBC in groups with different grades of hypertension

\begin{tabular}{llll}
\hline Indicator & I Grade & 2 Grade & 3 Grade \\
\hline & $\mathrm{N}=44$ & $\mathrm{~N}=30$ & $\mathrm{~N}=1 \mathrm{I}$ \\
AAEO $(\mathrm{mcm})$ & $47,5 \pm \mathrm{I}, 4^{* *}$ & $47,6 \pm 2,8$ & $52,7 \pm 3,2$ \\
$\begin{array}{l}\text { Asymmetry of } \\
\text { oscillation }\end{array}$ & $-\mathrm{I}, 3 \mathrm{I} \pm 0,32$ & $-2,44 \pm 0,25$ & $-\mathrm{I}, 49 \pm 0,52$ \\
$\begin{array}{l}\text { The percentage of } \\
\text { mobile RBC (\%) }\end{array}$ & $98,3 \pm 0,7^{*}$ & $98,5 \pm 0,5$ & $96,0 \pm 0,9$ \\
\hline
\end{tabular}

Note: The reliable indicator of differences between $I^{\text {st }}$ and $3^{\text {rd }}$ groups $*_{p}<0,05$; $* * p<0,0$ I

The decrease in AAEO in patients with hypertension can be explained by a disturbance of the structure and function of cell membranes, which are that facilitated ion transfer through the cell membrane proceeds with greater speed in the presence of hypertension. ${ }^{6,14}$ In the study of hypertension in patients on programmed hemodialysis Boero et al. ${ }^{14}$ measured RBC Na/K ATPase activity and noted lower pump activity in patients with hypertension as opposed to patients with normal BP. ${ }^{2}$ In further studies, data on 
the inhibition of $\mathrm{Na} / \mathrm{K}$ ATPase are presented, due to which there is an increase in intracellular sodium and cytosolic calcium, leading to increase in level of basal vascular tone and vascular response to vasoconstrictors. ${ }^{6,2,13}$ During ABPM, high correlations of AAEO with the nocturnal BP decrease $\left(\mathrm{SBP} r_{s}=0.73, p<0.001 ; \mathrm{DBP} r_{s}=0.63\right.$, $p<0.001)$ and heart rate $(\mathrm{rs}=-0.64, \mathrm{p}<0.001)$ were proven. Nocturnal $\mathrm{BP}$ decrease is an indicator not only determining the type of circadian rhythm of BP, but also significantly affecting the progression of left ventricular hypertrophy, the risk of cardiovascular complications and, eventually, the survival rate of patients with hypertension. Thus, the disturbance of cell membranes can determine the prognosis of the disease, which in turn determines the strategy of antihypertensive and organ-protective therapy. Therefore, a comparison of membrane disorders in different antihypertensive therapy was carried out.

In patients receiving $\mathrm{CCB}$ therapy, the level of AAEO was $51.5 \pm 5.4 \mathrm{mcm}$; ACE inhibitors- $44.6 \pm 5.8 \mathrm{mcm}$; BB $-46.6 \pm 1.1$ $\mathrm{mcm}\left(p_{1-3}<0.05 ; p_{1-2}>0.05, p_{2-3}<0.05\right)$. The asymmetry of erythrocyte oscillation in patients receiving ACE inhibitor therapy was $-2.4 \pm 0.3$, $\mathrm{CCB}-0.6 \pm 1.4 ; \mathrm{BB}-0.2 \pm 0.3\left(p_{1-3}<0.05 ; p_{1-2}<0.05, p_{2-3}>0.05\right)$ (Figure 1). Several studies have shown that $\mathrm{CCB}$ can protect the cell from damage of plasma membranes (ischemic, physical or chemical), leading to apoptotic cell death or necrosis in conditions of prolonged increasingof intracellular concentration of $\mathrm{Ca}^{2+} \cdot{ }^{10-12}$ This conclusion confirms the data obtained by us about the positive effect of $\mathrm{CCB}$ monotherapy on the electric charge of the RBC membrane $(\mathrm{p}<0.05)$. Also, in the absence of CCB in combined antihypertensive therapy, the lowest rates of AAEO were observed (combination of BB and ACE inhibitors; 42.3 $=6.3 \mathrm{mcm}, \mathrm{p}<0.05$ ).

The triple combination (CCB, BB, IRA) more effectively stabilized the charge of cell membranes, which was confirmed by a higher level of AAEO in patients $(56.3=6.9 \mathrm{mcm}$; $\mathrm{p}<0.01)$. The obtained results indicate the need for the use of triple combination in low-dose regimens in patients with hypertension receiving programmed hemodialysis. High rates of AAEO were also revealed in patients taking $\mathrm{CCB}$ with IRA, CCB with $\mathrm{ACE}$ inhibitors, $\mathrm{CCB}$ with $\mathrm{BB}(53.7 \pm 3.7,51.6 \pm 5.8,48.0 \pm 3.4 \mathrm{mcm}$ respectively, Figure 2). Thus, among the double combinations, the combination of CCB and IRA is most effective in stabilizing the charge of cell membranes. A number of studies have shown the role of autonomic homeostasis disorders in the pathogenesis of hypertension in patients with CKD, in this regard, the use of selective IRA is necessary., ${ }^{3,9}$ Our data show that IRA can positively affect the properties of cell membranes of the body, which can open up new priorities in their appointment.

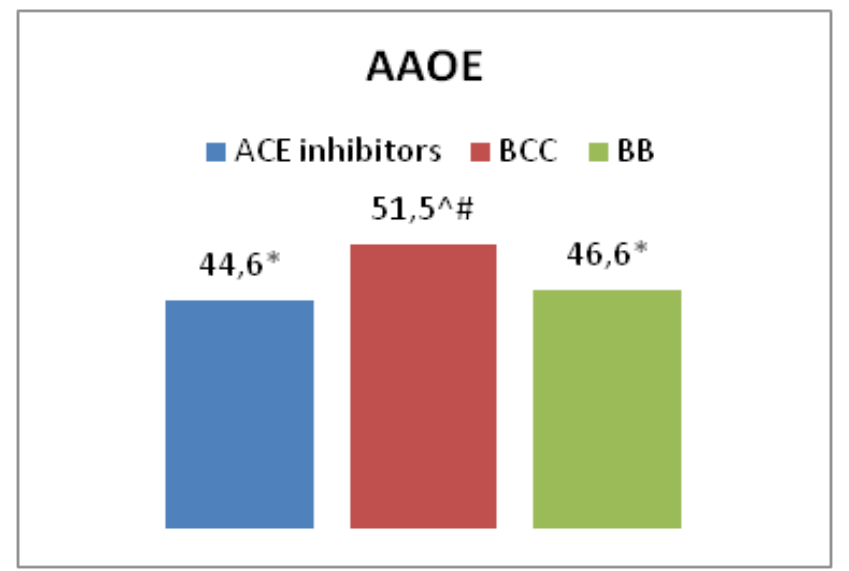

\section{Asymmetry of RBC oscillation}

- ACE inhibitors $\square \mathrm{CCB} \square \mathrm{BB}$

$0,2^{\wedge}$
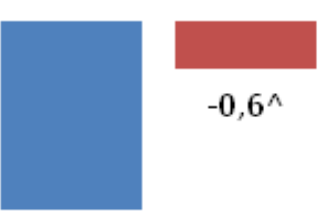

$-0,6^{\wedge}$

Figure I Characteristics of EME in patients receiving monotherapy.

Notes: In comparison with patients received CCB therapy:*- $p<0,05 ; \mathrm{ACE}$ inhibitors: ${ }^{\wedge}-p<0,05 ; \mathrm{BB}:{ }^{\sharp}-p<0,05$.

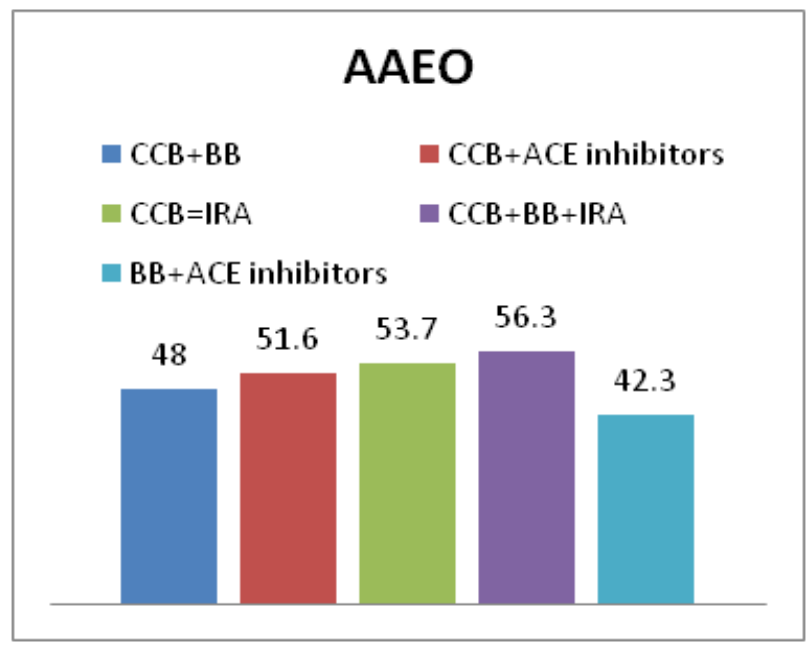

\section{Asymmetry of RBC oscillation}
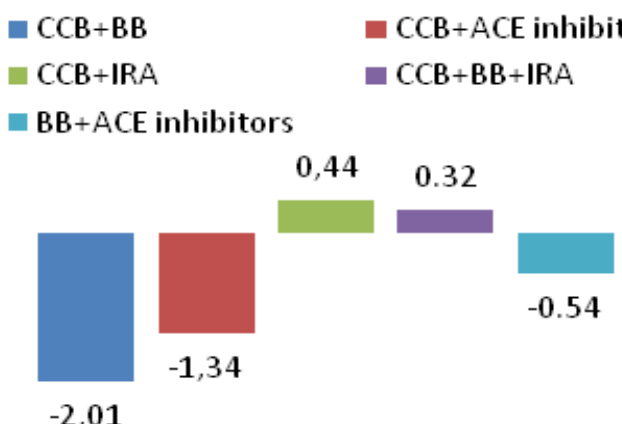

Figure 2 Characteristics of EME in patients receiving combination therapy. 


\section{Conclusion}

Indicators of electrophoretic mobility of erythrocytes in patients treated with programmed hemodialysis, have their own characteristics, in the form of a significant increase in the average amplitude of erythrocyte oscillations $(48.9 \pm 6.7 \mathrm{mcm})$, compared with the group of practically healthy individuals $(28.4 \pm 3.2 \mathrm{mcm})$. The level of AAEO depends on the duration of dialysis therapy (the level is lower, if the duration is from 1 year to 6 years), etiological factor (the level is lower in case of polycystic kidney disease), the presence and grade of hypertension. The value of AAEO is highly correlated with the level of nocturnal BP decrease. High EME values were determined in monotherapy with slow calcium channel blockers and triple antihypertensive therapy $(\mathrm{BB}, \mathrm{CCB}, \mathrm{IRA})$.

\section{Acknowledgments}

None.

\section{Conflicts of interest}

The author declares there is no conflict of interest.

\section{Funding}

None.

\section{References}

1. Aladashvili NZ. Electrophoretic mobility of peripheral blood erythrocytes in children with nonspecific inflammatory diseases. Dissertation for the degree of $\mathrm{PhD}$. Moscow. 2005. p. 93.

2. Boero R, Castellani M, Squazzoni F. Individual behavior and macro social properties. An agent-based model. Computational and Mathematical Organization Theory. 2008;14(2):156-174.

3. Borovkova N Yu, Borovkov NN, Ivanchenko E Yu. Assessment of heart rate variability in patients with renoparenchimatous arterial hypertension with preserved renal function. Therapy. 2015;3(3):39-45.

4. Deryugina AV, Martusevich AA, Khramova Yu N, et al. Electrophoretic mobility of erythrocytes in inflammation. Vyatka Medical Bulletin. 2016;4(52):57-60

5. Erovichenkov AA, Sadovskaya GV, Pak SG. Electrophoretic mobility of erythrocytes in patients with various forms of erysipelas in the dynamics of the disease. Therapeutic archive. 2001;11:73-75.

6. Khan MB, Khasanov NR, Oslopov VN. Membrane disorders as the basis of dyslipidemia and arterial hypertension. Practical medicine. 201;3(71):34-36.

7. Kirkovsky VV, Levin VI, Mitkovskaya NP. Electrophoretic mobility of erythrocytes in patients with rheumatoid arthritis in the process of extracorporeal autohemomagnitotherapy. Health care. 2002;1:12-18.
8. Krylov VN, Deryugina AV. Change in electrophoretic mobility of isolated erythrocytes under the action of stress factors. Hematology and Transfusiology. 2011;5:18-21.

9. Mikhailov AA, Shilov AM, Spassky AA. Domestic and foreign experience of the use of Physiotens in the treatment of "Diseases of civilization". Archives of internal medicine. 2012;100:41-45.

10. Minushkina LO. Calcium antagonists in the treatment of hypertension: features of Lercanidipine. Russian cardiology journal. 2015;2 (118):110-114

11. Musina NS, Semenova RI, Seidumanov MT. Effectiveness of antihypertensive therapy in patients on hemodialysis. Bulletin of $\mathrm{Kaz}$ NMU. 2015;1:255-256.

12. Nakamura T, Sato E, Fujiwara N. Calcium channel blocker inhibition of AGE and RAGE axislimitsrenal injury in nondiabetic patients with stage I or II chronic kidney disease. Clin Cardiol. 2011;34(6):372-377.

13. Orlova OV, Egorova SN, Oslopov VN. Study of dimethyl sulfoxide influence on cell membrane permeability. Kazan medical journal. 2011;92(6):901-904.

14. Postnov Yu V. Primary hypertension as a pathology of cell membranes 1987. p. 92.

15. Rakhov DA, Yudanova LS, Rubin VI. Functional properties of erythrocyte membranes in patients with chronic glomerulonephritis. Urology and Nephrology. 1992;4-6:31-33.

16. Shklyaev AE, Shishkin AV. Electrophoretic mobility of erythrocytes in Riboxin solutions in patients with chronic gastroduodenitis and duodenal ulcer. In the collection: Transactions of young scientists of Russia Viter V.I. Collection of materials of III Medical Congress. Izhevsk State Medical Academy of the Ministry of Health of the Russian Federation. 2000. p. 283-286.

17. Sigitova ON, Arkhipov EV. Structural and functional disorders of nephrocyte cell membranes in chronic kidney diseases. Kazan medical journal. 2011;92(6):887-890.

18. Solovieva AA, Maksimov NI. Features of electrophoretic mobility of erythrocytes in myocardial infarction in patients with metabolic syndrome. Health, demography, ecology of Finno-Ugrians. 2010; 3:48.

19. Vasilkova EV. Influence of various methods of treatment on microelectrophoretic mobility of erythrocytes in women with chronic inflammatory diseases of the pelvic organs. Author's abstract of dissertation for the degree of PhD. Ivanovo, 2012. p. 23

20. Zhitkova Yu V, Khasanova DR, Oslopov VN. Membrane characteristics and vascular cognitive disorders. Neurology, neuropsychiatry, psychosomatics. 2017;9(4):10-16. 